\title{
A survey on hardware start-ups, tough-a-head in India
}

\author{
Ayushi Nigam, Dr. Hari Om Sharan
}

\begin{abstract}
According to present scenario in India, there is a need of development of small scale systems to solve the real life problems of our country and also to improve the technological and economical growth of our country. According to survey it is found that in the world market of computer software and services, the software systems exporting rate of India is quite high but as we see the exporting rate for the hardware systems which is quite low as compare to USA, Europe, China and Japan. China is the one of the top most exporting country. It exports 950 billion products to India. If we consider the export scenario of India, in this ranking India is ranked at 19th position. In order to improve the exporting rate of India, there is a need of development of small scale systems, which is not only helpful in improving the technological growth rate but also increases the exporting rate of our country. This Thesis focuses on development of methodologies. These methodologies serve as guideline for developing small scale systems. Thesis focuses on developing a micro level architecture which can be used as heart/core of development of small-scale systems. The architecture will be designed in such a way that it can integrate with its derived architectures autonomously hence giving rise to self-integrating macro architecture of course with some domain expert intervention.
\end{abstract}

Index Terms - methodology, export, hardware system, micro level architecture, small scale system, self integration

\section{INTRODUCTION}

As we know that India is one of the most recently growing and developing country of the world, but still we are facing the some problems in field of hardware development, According to NASSCOM Zinnov Startup report 2016 "Hardware start-ups have some limitation in term of obsolescence, manual intervention, inventory and updations"

Consider the case of Vaibhav Chandra who returned to India in 2013. He wanted to pursue MIT project called "Eye Netra", a self diagnostic eye test technology but in India he did not find a laboratory to test the product, a place where he can develop the prototype, manufacture products in large volumes"

According to Som Shubhro Pal Chaudhury, a renowned face of the corporate world, India witnessed tremendous growth in software front but miserably failed on manufacturing front. He stated "Around 2010-12 we saw the emergence of the system design trend with many multinational corporations (MNCs) and design houses beginning to do design work in India..... This was a good news for Design in India”, but manufacturing was still being done overseas".

According to The Hindu newspaper "India's software exports success has been offset by rising hardware imports. The inability to develop a domestic hardware base, amidst

Ayushi Nigam, M.Tech. Scholar, CSE Department, FET, RAMA University, KANPUR

Dr. Hari Om Sharan, Professor, CSE Department, FET, RAMA University, KANPUR rising demand, will impact the BoP”. The value added in India's Computer programming and related services industry rose from \$2974 million in 2000 to \$19568 million in 2014, but in the sector of producing office machinery after rising from $\$ 209$ to $\$ 775$ million in 2011 , fell to $\$ 281$ million by 2014. The Stagnation in domestic hardware production has occurred in a period when the computer use has been rising rapidly in the country and the government has been pushing for computerisation in its own departments, in the banking sector and among the public at large.

According to data from WTO, the consequence of the combination of stagnation in production and expansion in use, has been a significant increase in the imports of computer hardware. Thus imports of Electronic data processing and office equipments rose from $\$ 1413$ million in 2000 to $\$ 4481$ in 2008 and after a marginal fall in crisis year 2009, resumed climb to reach $\$ 8293$ million in 2015 . So as software services exporter India's growth is increasing day by day.

According to the report of The Hindu's Commercial site-www.businessline.com "India's computer software/ services and IT enabled services (ITes) has grown $3.8 \%$ to \$111billion during 2016-17"

For example, VLSI industry exists in India from past 32-35 years The areas covered by VLSI industry in India are Bangalore, Hyderabad, Delhi NCR region, 18 out of 25 chip designing companies had open there chip designing centres in India in the above mentioned areas, Indian chip designers provide design services or work at the subsidiaries of global chip companies, especially US and European firms but they are providing design services for IC design at very low rate, According to VLSI Society of India, estimates the IC design population in India to be around 11,000 while those working on the embedded software number to touch 60,000 . Other than this many IITs, NITs, research organization of India are not able to develop even a simple Wi-Fi model like China did. China develop "ESP 8266 Wi-Fi model" having a cost of 200 to 1000 Rs. and a dual core processor is inbuilt in it. In this way we can say that we are getting a dual core processor in just 1000 Rs. None of the Indian is capable to develop this type of Chinese or western world components.

According to the ISA-Frost \& Sullivan report "the total number of design starts in the Indian VLSI design market was estimated at 320 in 2005" which was quite low.

On the basis of above survey, Hardware development is a problematic case in India, there is a lack of fixed methodology which provides an atomic base for the development of any hardware system. Each hardware system is composed of several sub systems, for fabrication of any sub system requires focusing on critical areas and complexities that will get arisen during the designing process, because each sub

System requires specific domain expertise then these sub systems are self integrated autonomously to form a big system.

The issues due to which the hardware development is troublesome in India are discussed below: 


\subsection{Financial Aspect}

One of the major problems that we are facing for the hardware start-ups is to get financial aspect sorted out. Hardware start-ups require more funding than the software starts-ups as assembling and developing the product from scratch is one that demands a considerable amount of capital. As we know developing the prototype of a product, which is a meticulous task that requires a great deal of time and effort and you cannot just rely on one prototype. While this process is time consuming and taking the successful prototype to level of mass manufacturing and also procuring the raw materials for the product at affordable prices can be difficult. In India we don't have all sort of testing tools and equipments available for testing the prototype, If the prototype get finalized, then development get started requires a lot of capital to be invested for the fabrication and testing of complete system.

1.2 Lack of Well Equipped and Well Furnished laboratories In India, it is another one type of major issue that is preventing the growth of hardware start-ups in India that is the lack of proper testing tools and laboratories. This issue also resist the developers to start development procedure in India, As we already know the very famous case of Vaibhav Chandra who belongs to IIT Delhi and expertise in Mechanical development came at India with his MIT project "EYE NETRA" with lot of hopes, but he really get very much disappointed when he doesn't found proper tools even for the testing of prototype of his project.

We can also consider the case of IIT Kanpur Students who get felicitated for developing the Braille System Slate and also get awarded by "Gandhian Young Technological Innovation Award-2017" for developing a prototype of a Braille slate called 'Anubhav' at a function held at Rashtrapati Bhawan on March 5.

Braille system is very useful device for blind person because Braille is the language used by the vision impaired person for their study and written communication. Such Braille text is printed through indentation of dots appearing in specified patterns on a special quality paper (120-140 gsm) as shown in Fig 1,

For production these dots requires a print head imposed on Braille Embosser require Solenoids, The Solenoids that is used in print head is CMERI-9309 Solenoid shown in Fig 2, In India due to deficiency of CMERI-9309 Solenoids, IIT Kanpur students did not succeeded in the development of Braille System in India.

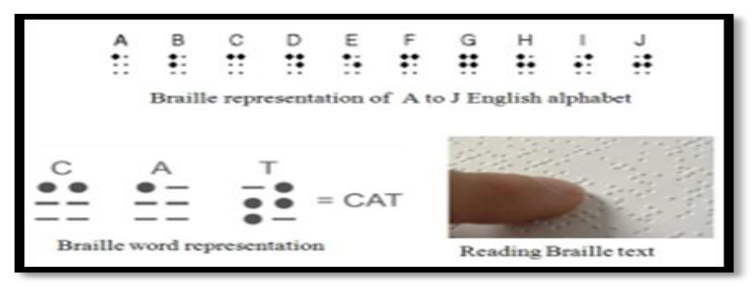

Fig: 1 Braille Text in Specific Pattern

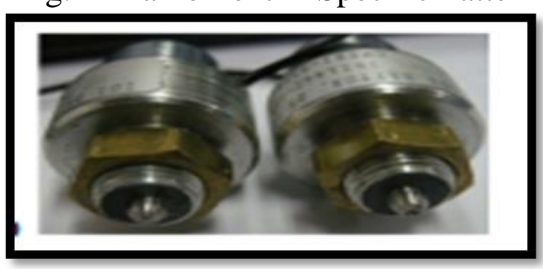

Fig: 2 CMERI-9309 Solenoids

\subsection{Gaining the Support from Investors}

Gaining a support from investors becomes really a tough task as being a new player in the market, most of the companies are not ready to trust your product and invest in it. Hardware Developers in India becomes so much disappointed when they found that even Government of India also not ready to rely on their project which not only exploits the hope of developers also decreases the growth in field of Hardware development. Due to this reason Hardware exporting rate of India is also quite low

If I talk about software services, According to NASSCOM "India's IT exports are expected to grow at 7-9 percent to be at $\$ 135$ billion-\$137 billion in 2018-19, the report further said. The IT exports during the current financial year are projected to be $\$ 126$ billion, a growth of 7-8 percent over last year." This report shows that the software services exporting is quite low as compare to hardware systems, which represents that a very strong support is needed to hardware developers by investors and also by Indian government.

\subsection{Lack of Well Charted Business Plan}

In India there is lack of fixed methodology to start design procedure in India. As we already studied about software engineering models like: Waterfall model, Iterative Prototyping model, Spiral model, Kanban development model etc. These models provide the guidelines for the development of successful software. These generic model can be used for the development of any kind of software for example waterfall model can not only be used for development of system software, but it can also be used for designing of e commerce software,operating system and also for fabrication of many other kind of soft ware's.

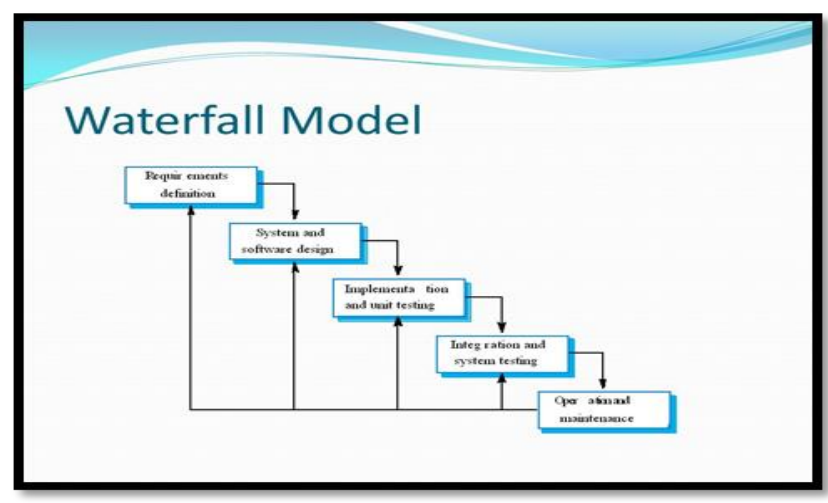

Fig: 3 Guidelines for Waterfall Model

Similarly, In case of Hardware system there is an absence of such kind of generic development model by using which we can perform the hardware development procedure in a systematic and also in proper scheduled manner.

\subsection{Lack of Distribution Platform}

In India the area covered by "hardware technology" is very limited but the other countries like: Japan. China, Germany, Europe are spread over large area. This is also one of the important reason due to which entrepreneurs feel somewhat hesitated in trying to invest his money in field of hardware development

According to the NASSCOM-Zinnov Start-up Report, 2016 , in the last few years, the technology sector has received a boost from the Government of India's innovative ventures 


\section{International Journal of Engineering and Technical Research (IJETR) \\ ISSN: 2321-0869 (O) 2454-4698 (P) Volume-8, Issue-12, December 2018}

such as Digital India, Startup India and Make in India initiatives. These have helped empower budding new entrepreneurs and enthusiastic startups, paving the way to improve the tech infrastructure in the country, as well as give the manufacturing sector a makeover.

This report shows that Government of India is not only improve infrastructure and manufacturing sector in India but also trying to improve market sector of India so that entrepreneurs feels trust worthy area to invest their money in the field of Hardware development

\section{RELATED WORK}

As the above mentioned report show that Government is taking initiative and innovative step in field of hardware development, but this is only the beginning to hold a toe in field of technology but this is not sufficient for competing with countries like China, Japan, Germany, USA and Europe. As we talk about USA, it is like the dean of IT Industry School or you could call it the Godfather of IT Hubs. Silicon Valley is the biggest IT Hub in the world. All the big names have centers there i.e. Apple, Microsoft, Facebook, Google, Yahoo!, Amazon etc.

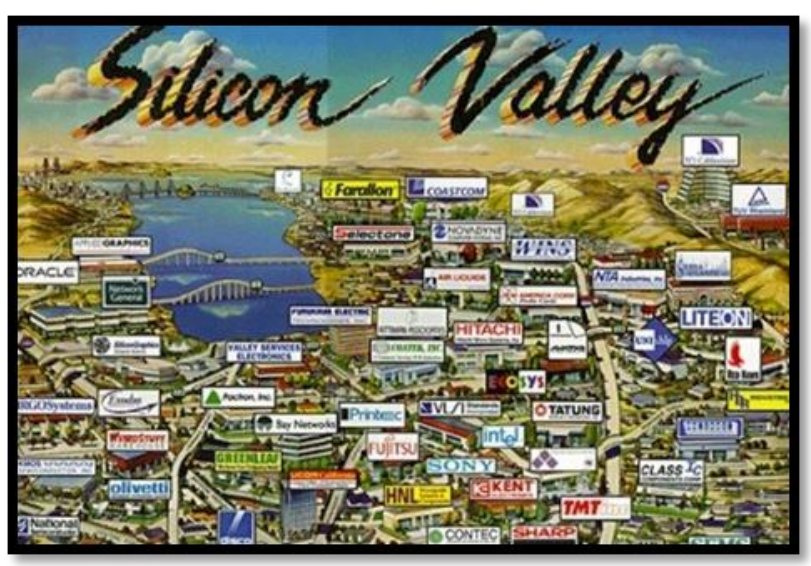

Fig: 4 Silicon Valley, Major IT Hub

So to compete with such countries there is a strong and urgent need of methodology or an architectural technique that is proved to be successful in field of hardware development.

\section{CONCLUSION}

In conclusion, it is true that the ecosystem surrounding hardware and manufacturing is a competitive one, with global giant companies from China, America, and Germany. A project called the Intel Maker Lab has since been launched to offer infrastructure, tools, and guidance as part of the 'Make in India' drive. It has further joined hands with IIT Mumbai and the Department of Science \& Technology, to launch Plug-in, a hardware startup incubator, to support startups from proof-of-concept to the final product.

In India on the basis of survey it is found that Government of India taking initiative by launching different kinds of policies in the technology sector such as Digital India, Startup India and Make in India but this is not sufficient step.

As according to VLSI society estimation VLSI design estimate was 11000 in 2006 and according to their prediction it will become 60000 in 2015 but we can't say that this production of IC design is sufficient for improving overall economic growth of country.
In India we always talk about IOT and other things but till now all the IITs, NITs and research organizations are not capable developing the single micro controller chip.

For example The Raspberry $\mathrm{Pi}$ is a series of small single-board computers developed in the United Kingdom by the Raspberry $\mathrm{Pi}$ Foundation to promote teaching of basic computer science in schools and in developing countries.

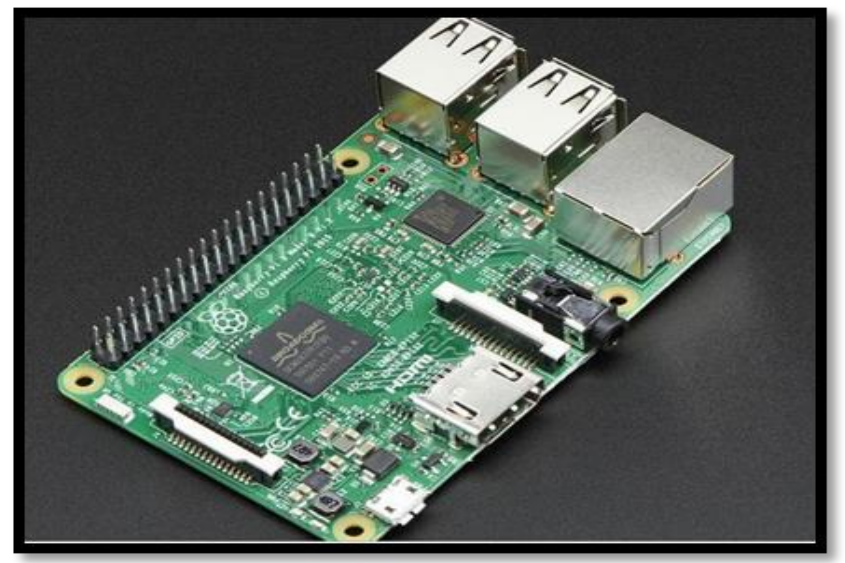

Fig: 5 Raspberry model B+

So in this way major and prime objective of this survey paper is to bring attention of all the peoples who are technical professionals and research scholars, towards the field development of hardware systems. There is essential need of generic model which provides the atomic base for the development of any hardware system which is not useful in improving the exporting rate but also useful in improving economic growth of our country.

\section{ACKNOWLEDGEMENT}

All the above mentioned information is true as per my consideration, I Hope this paper will be proved to be useful for person who are the part of technology sector and tries to improve the hardware development scenario in India.

\section{REFERENCES}

[1] India Brand Equity Foundation "Information Technology and Information Technology Enabled Services" 1 July 2017

[2] CP Chand Shekhar, Jayati Ghosh "The imbalance that underlies Indis's Software Success" published in The Hindu 13 March 2017.

[3] Tim Stock and Gunther Seliger "Methodology for Development of Hardware Start-ups" published in Trans Tech Publication 31 March 2016

[4] Suparna Goswami “ India's Harware Startups Have a Tough road ahead of them" published in Forbes Media 2 Nov 2016

[5] Aravind Gowda "India takes lead in Chip design" published in Rediff. Com-business Standard 28 Nov 2006

[6] S.Jain1 ,S.Majumder2 and K.J.UKe2 Tech.Off.1 Scienist2,CSIR-Central Mechanical Engineering Research Institute Durgapur-713209, India "An Experimental Driven Approach of Braille Embosser Print Head Design Using Analytical and Computational Techniques" Proceedings of the 1st International and 16th National Conference on Machines and Mechanisms (iNaCoMM2013), IIT Roorkee, India, Dec 18-20 2013

[7] Gandhi Young Technological Innovation Awards(GYTI) “gyti.techpedia@sristi.org”5 Mar 2017

[8] Vishal Krishna "IT exports from India expected to grow 7-9 pc to $\$ 137$ B in 2018-19: Nasscom" published in YourStory.com posted on 20 Feb 2018

[9] "Major IT hubs across the world" published in webmuch site 2013 